\title{
Tuberculosis involving the oral cavity
}

KATHLEEN A FERGusON, MD, FRCPC, DAVID G MCCORMACK, MD, FRCPC

\begin{abstract}
KA Ferguson, DG McCormack. Tuberculosis involving the oral cavity. Can J Infect Dis 1993;4(1):1214. The oral cavity is a rare site for extrapulmonary tuberculosis. A case is reported of a young woman with dysphagia and oral ulceration. The original mucosal biopsy was negative on smear for acid-fast bacilli, and the patient subsequently developed pulmonary symptoms. A diagnosis of Mycobacterium tuberculosis was ultimately made on open lung biopsy. Complete resolution of both mouth lesion and chest involvement occurred with standard antituberculous therapy.
\end{abstract}

Key Words: Oral ulcer, Pulmonary, Tuberculosis

\section{Tuberculose dans la cavité buccale}

RÉSUMÉ: Il est rare d'observer la tuberculose extra-pulmonaire dans la cavité buccale. Un tel cas a été rapporté chez une jeune femme souffrant de dysphagie et d'ulcération buccale. La biopsie originale de la muqueuse s'est révélée négative au frottis pour déceler le bacille en l'absence d'acide et la patiente a subséquemment développé des symptômes pulmonaires. Un diagnostic de tuberculose à Mycobacterium tuberculosis a finalement été posé à la biopsie pulmonaire. Une guérison complète des lésions buccales et pulmonaires a été obtenue à l'aide du traitement antituberculeux classique.

$\mathrm{T}$ HE INCIDENCE OF TUBERCULOSIS HAS BEEN FALLING steadily for many years, but recently this decline has reached a plateau (1). The clinician's index of suspicion remains high for certain groups (ie, native Canadians, human immunodeficiency virus [HIV]-positive persons), but tuberculosis still occurs in normal hosts. A case of a young healthy woman who presented with oral ulceration from disseminated tuberculosis is described.

\section{CASE PRESENTATION}

A 35-year-old, Caucasian, married woman presented with a three-month history of odynophagia in Novem- ber 1989. A lesion on the soft palate was noted and biopsied, and this revealed ulceration, noncaseating granulomata and foreign body giant cells. Ziehl-Neelsen stain was negative for acid-fast bacilli. This specimen was not cultured for tuberculosis. Fungal stains were positive, consistent with a superficial candidal infection superimposed on a granulomatous process. The patient received a course of topical antifungal therapy with no response. A chest radiograph was not performed.

The patient presented to her physician in late 1989 with progressive shortness of breath on exertion, fatigue and a new nonproductive cough. She also complained of a sore throat and odynophagia. She denied

Division of Respiratory Medicine, Victoria Hospital, London, Ontario

Correspondence and reprints: Dr DG McCormack, Victoria Hospital, 375 South Street, London, Ontario N6A 4G5. Telephone (519) 667-6767

Received for publication May 13, 1991. Accepted August 26, 1991 


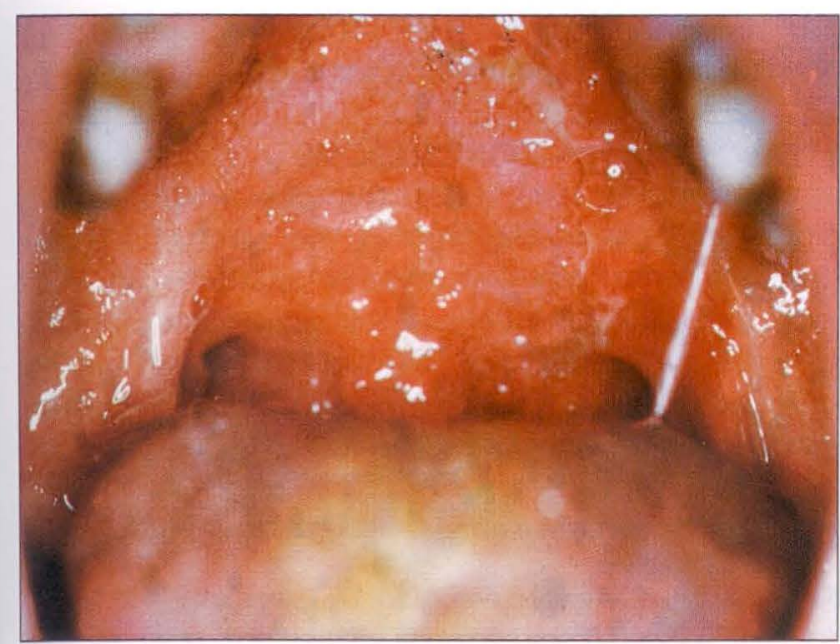

Figure 1) Diffuse, slightly raised, ulcerated lesions on the soft palate and oropharynx

sputum, hemoptysis, fever, rash or joint complaints. She denied risk factors for HIV infection. The patient was a lifelong resident of southwestern Ontario. She smoked 10 to 15 cigarettes a day and was on no medication. She denied any exposure to tuberculosis. On physical examination her vital signs were stable and she appeared well. There was no clubbing, lymphadenopathy or hepatosplenomegaly. There were diffuse, slightly raised, ulcerated lesions on the soft palate and oropharynx (Figure 1) which had been present for several months. The remainder of the physical examination, including chest examination, was unremarkable. A tuberculosis skin test was negative in late 1989.

A chest $\mathrm{x}$-ray demonstrated diffuse nodular interstitial lung disease with an upper zone predominance and no hilar adenopathy (Figure 2). A computed tomography scan showed diffuse nodular and airspace disease with no hilar or mediastinal lymphadenopathy.

A repeat skin test with 5 units of purified protein derivative in early 1990 was negative $48 \mathrm{~h}$ later. The differential diagnosis included sarcoidosis and tuberculosis, and as the patient was unable to produce sputum, a flexible bronchoscopy was performed. This included bronchoalveolar lavage and transbronchial biopsy of the posterior left upper lobe. Washings were acid-fast bacilli smear negative, and the transbronchial biopsy revealed chronic inflammation, nonspecific fibrosis and no evidence of granulomata or acid-fast organisms. Fungal and bacterial stains were negative.

The patient remained quite symptomatic, and in the absence of a diagnosis an open lung biopsy was performed which revealed caseating granulomata with acid-fast bacilli. Cultures were subsequently positive for Mycobacterium tuberculosis from the initial bronchial washings and the open lung biopsy, and there was no drug resistance. She was started on isoniazid, rifampin and pyrazinamide, and improved significantly. After three weeks of therapy the mouth lesions began to

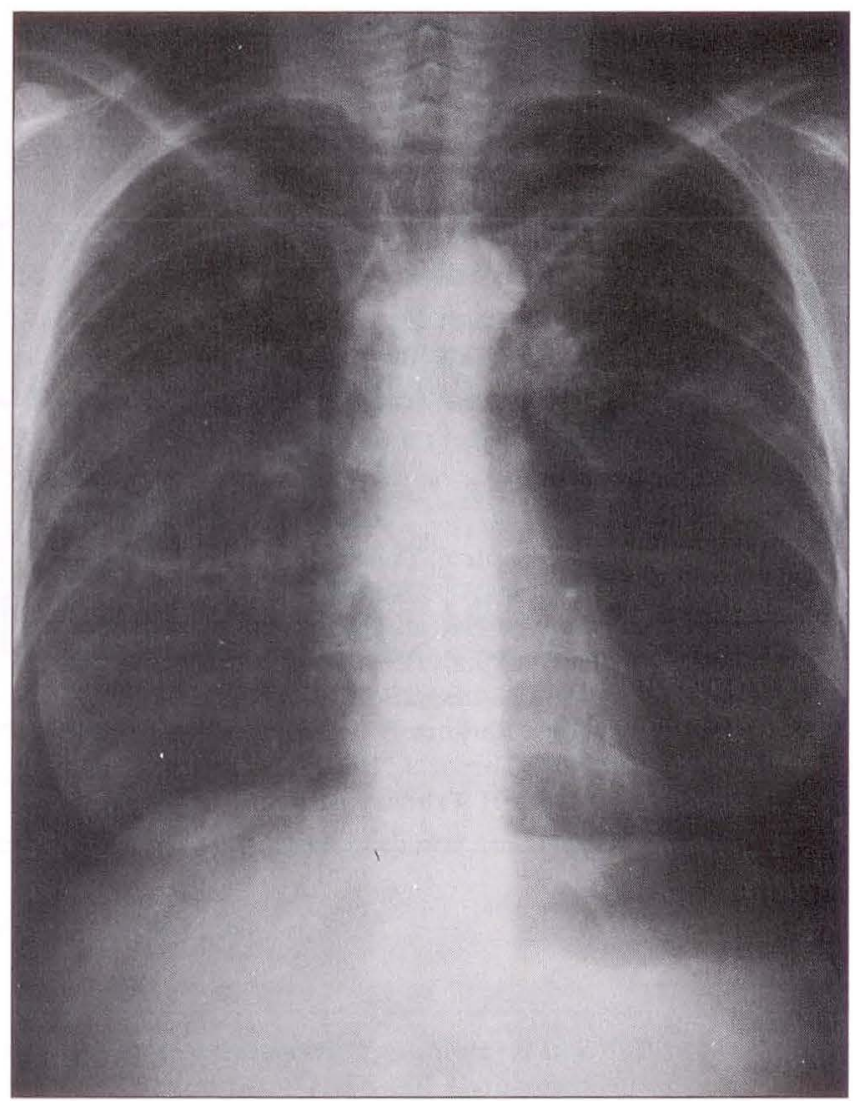

Figure 2) Chest $x$-ray demonstrating diffuse nodular interstitial lung disease with an upper zone predominance and no hilar adenopathy

improve and resolved after two months of therapy. The shortness of breath also completely resolved, and the chest $\mathrm{x}$-ray has improved with a few small residual nodules. The patient remains asymptomatic at one year of follow-up. Fortunately, she has had an excellent recovery from disseminated tuberculosis.

\section{DISCUSSION}

Tuberculosis of the oral cavity is a rare occurrence. In one large series reviewing the 10-year experience at a large inner-city hospital, 136 patients with extrapulmonary tuberculosis were reviewed, and only one patient had oral cavity involvement (2).

Oral cavity lesions in tuberculosis occur most frequently on the tongue, but are also seen on the gingiva and palate. They may be painful and may resemble a malignant ulceration. Biopsy generally reveals nonspecific inflammation, caseating granulomas and foreign body giant cells (3-5), but cultures are frequently negative for acid-fast bacilli (3-5). Oral ulcers may occur in primary or secondary tuberculosis (3-5), and it is important to test for pulmonary disease. Additionally, cultures for drug sensitivities are important. The differential diagnosis of the lesions of oral tuberculosis includes trauma, actinomycosis, syphilis, carcinoma, Wegener's granulomatous and aphthous ulceration. In 
the present patient the coexistent lung disease was suggestive of sarcoidosis; however, an open lung biopsy revealed acid-fast bacilli. The delay in diagnosis was likely related to the diffuse nature of the lung disease.

Treatment of extrapulmonary tuberculosis is the same as for pulmonary tuberculosis (6). A standard six- or nine-month course is acceptable and effective therapy.

The present patient had an unusual presentation of tuberculosis involving the oral cavity which preceded the pulmonary symptoms. Once the diagnosis was es-

\section{REFERENCES}

1. Centers for Disease Control. Tuberculosis, Final Data United States, 1986. MMWR 1988;36:817-20.

2. Alvarez S, McCabe WR. Extrapulmonary tuberculosis revisited: A review of experience at Boston City and other hospitals. Medicine 1984;63:25-55.

3. Verma A, Mann SBS, Radotra B. Primary tuberculosis of the tongue. Ear Nose Throat J 1989;68:718-9.

4. Hashimoto Y, Tanioka H. Primary tuberculosis of the tablished and appropriate antituberculous therapy started, a good response occurred.

\section{CONCLUSIONS}

Tuberculosis remains an important disease entity which must be considered in the setting of diffuse pulmonary disease. Atypical presentations are common, and a high index of suspicion must be maintained in order to establish the diagnosis and undertake appropriate therapy. The prognosis for treated extrapulmonary tuberculosis is excellent.

tongue: Report of a case. J Oral Maxillofac Surg 1989:47:744-6.

5. Haddad NM, Zaytoun GM, Hadi U. Tuberculosis of the soft palate: An unusual presentation of oral tuberculosis. Otolaryngol Head Neck Surg 1987:97:91-2.

6. Perez-Stabe EJ, Hopewell PC. Current tuberculosis treatment regimens: Choosing the right one for your patient. Clin Chest Med 1989;10:323-39. 


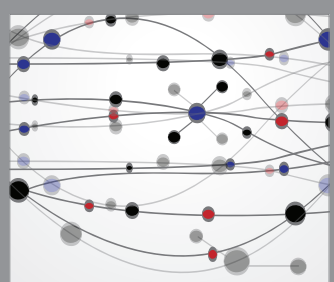

The Scientific World Journal
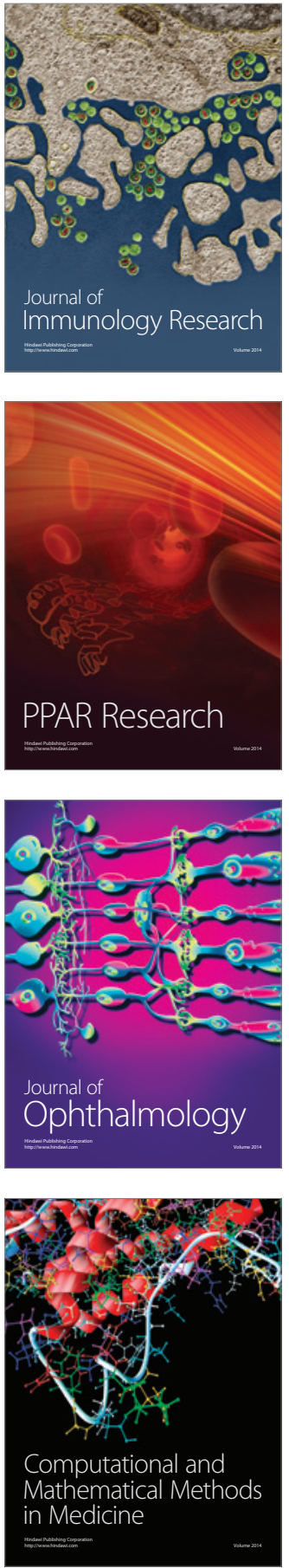

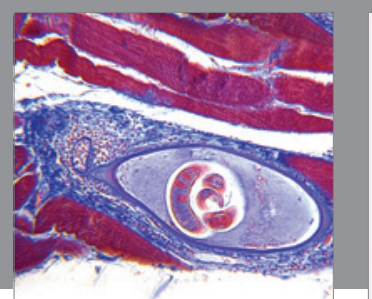

Gastroenterology Research and Practice

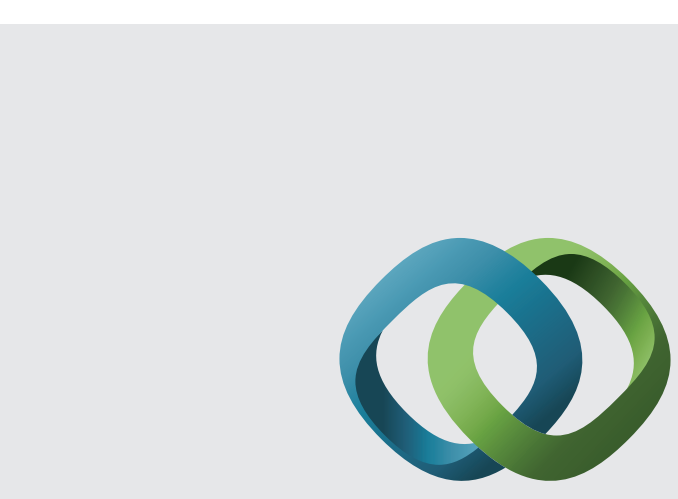

\section{Hindawi}

Submit your manuscripts at

http://www.hindawi.com
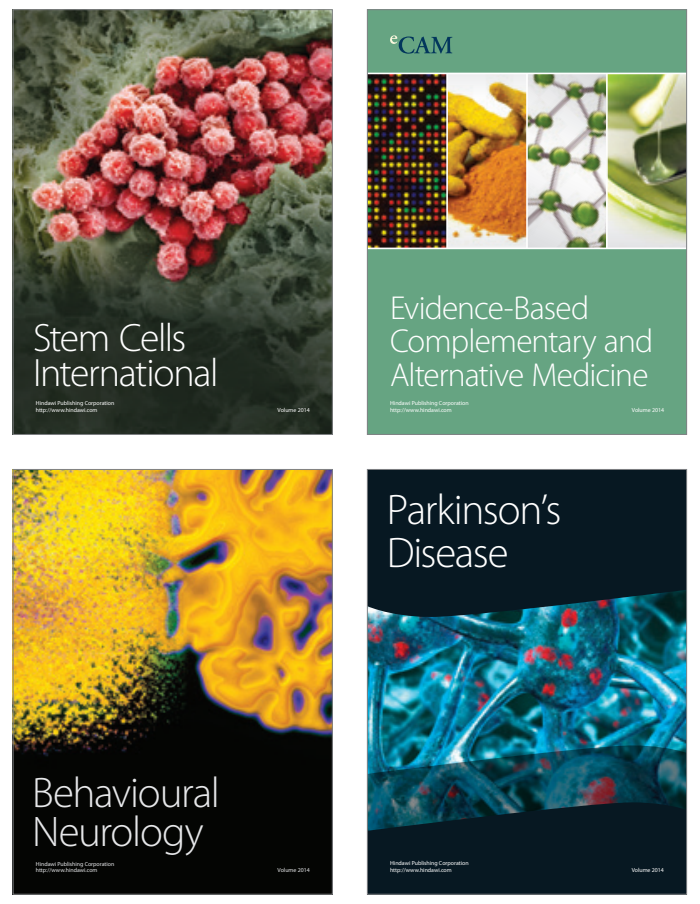
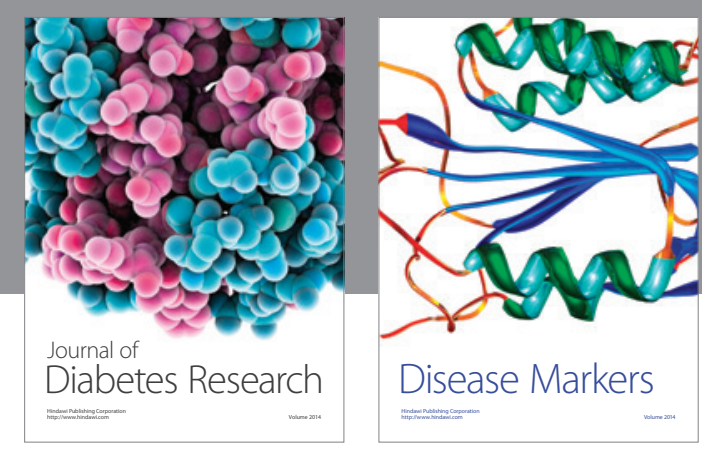

Disease Markers
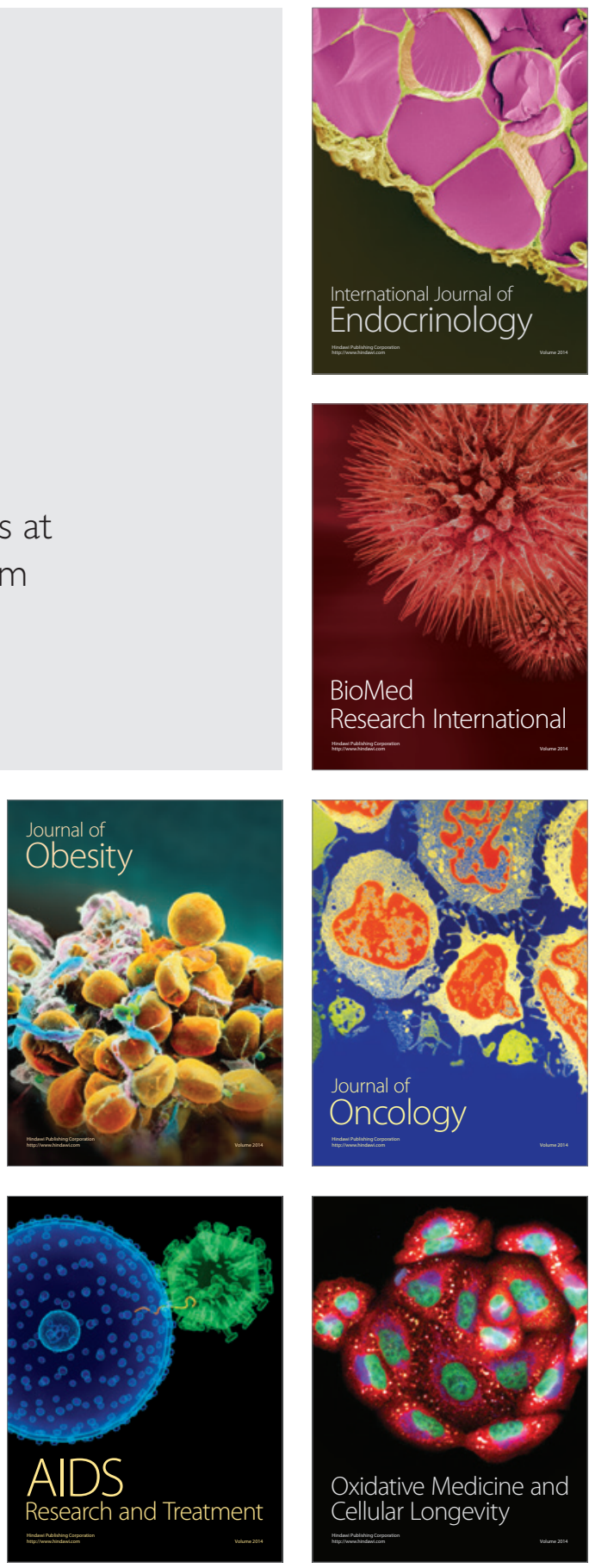